\title{
Activated $\delta$-opioid receptors inhibit hydrogen peroxide-induced apoptosis in liver cancer cells through the PKC/ERK signaling pathway
}

\author{
KAIQI JIA ${ }^{1^{*}}$, DEGUANG SUN ${ }^{1 *}$, SUNBIN LING $^{1}$, YU TIAN ${ }^{1}$, \\ XUEJUN YANG ${ }^{1}$, JIDONG SUI $^{1}$, BO TANG $^{2}$ and LIMING WANG ${ }^{1}$ \\ ${ }^{1}$ Department of General Surgery, The Second Affiliated Hospital of Dalian Medical University, \\ Dalian, Liaoning 116027; ${ }^{2}$ Department of Hepatobiliary Surgery, Affiliated Hospital of \\ Guilin Medical University, Guilin, Guangxi 541001, P.R. China
}

Received September 29, 2013; Accepted April 14, 2014

DOI: $10.3892 / \mathrm{mmr} .2014 .2301$

\begin{abstract}
Apoptotic liver cancer cells have important roles in liver tumorigenesis and liver cancer progression. Recent studies have shown that $\delta$-opioid receptors are highly expressed in human liver and liver cancer cells. The present study aimed to investigate the role of activated $\delta$-opioid receptors on human liver cancer cell apoptosis and its interrelation with the mitochondria and the protein kinase C/extracellular-signal-regulated kinase (PKC/ERK) signaling pathway. $\mathrm{H}_{2} \mathrm{O}_{2}$ was used to induce apoptosis in human liver cancer cells. During apoptosis, mitochondrial transmembrane potentials were observed to decrease, cytochrome $c$ expression was found to increase and B cell lymphoma 2 (Bcl-2) expression decreased. These findings suggested that $\mathrm{H}_{2} \mathrm{O}_{2}$-induced apoptosis was mediated through the mitochondrial pathway. Of note, activated $\delta$-opioid receptors were observed to inhibit $\mathrm{H}_{2} \mathrm{O}_{2}$-induced apoptosis in human liver cancer cells. Following $\delta$-opioid receptor activation, the number of apoptotic liver cancer cells decreased, mitochondrial transmembrane potentials were restored, cytoplasmic cytochrome $c$ and Bcl-2-associated X protein expression decreased and Bcl-2 expression increased. These
\end{abstract}

Correspondence to: Dr Liming Wang, Department of General Surgery, The Second Affiliated Hospital of Dalian Medical University, 467 Zhongshan Road, Dalian, Liaoning 116027, P.R. China

E-mail: wangbcc259@yahoo.com.cn

Dr Bo Tang, Department of Hepatobiliary Surgery, Affiliated Hospital of Guilin Medical University, 15 Lequn Road, Guilin, Guangxi 541001, P.R. China

E-mail: dytangbo@163.com

*Contributed equally

Key words: $\delta$-opioid receptor, hepatocellular carcinoma, apoptosis, protein kinase $\mathrm{C}$, ERK signaling pathway data suggested that $\delta$-opioid receptor activation inhibited mitochondria-mediated apoptosis. In addition, activation of $\delta$-opioid receptors was observed to increase the expression of PKC and ERK in human liver cancer cells. Furthermore, upon inhibition of the PKC/ERK signaling pathway, the protective effect associated with the $\delta$-opioid receptor on liver cancer cell apoptosis was inhibited, which was not associated with the status of $\delta$-opioid receptor activation. These findings suggested that the PKC/ERK signaling pathway has an important role in $\delta$-opioid receptor-mediated inhibition of apoptosis in human liver cancer cells.

\section{Introduction}

Liver cancer cell apoptosis has an important role in the occurrence and development of liver cancer and is mediated through multiple pathways (1). Thus, the study of liver cancer cell apoptosis may have important clinical implications for the treatment of liver cancer and the maintenance of liver function. The $\delta$-opioid receptor is a member of the opioid receptor family and is highly expressed in several human organs. Studies have shown that activated $\delta$-opioid receptors stimulate the proliferation of myocardial cells in newborn rats (2) and have a protective role in ischemic-preconditioning of the heart and brain tissues $(3,4)$. A previous study by our group demonstrated that activated $\delta$-opioid receptors had a protective effect against apoptosis in liver cancer cells (5). These findings suggested that $\delta$-opioid receptors have important roles in cell survival and proliferation. In addition to the central nervous system and the heart, $\delta$-opioid receptors are highly expressed in liver and liver cancer cells $(6,7)$. Furthermore, the $\delta$-opioid receptor has been found to have a significant role in the occurrence and development of liver diseases, including hepatoma, viral hepatitis and hepatic cirrhosis (7-9).

$\mathrm{H}_{2} \mathrm{O}_{2}$ is commonly used to induce apoptosis (10). In the present study, different concentrations of $\mathrm{H}_{2} \mathrm{O}_{2}$ were added to cultured cell media for specific time periods. The mechanisms underlying reactive oxygen species-induced apoptosis include receptor activation, activation of the caspase cascade, 
modulation of the expression of B-cell lymphoma (Bcl)-2 family member proteins and mitochondrial damage (11). The $\mathrm{H}_{2} \mathrm{O}_{2}$ model of apoptosis mimics the physiological conditions of hepatic ischemia and hypoxia. Apoptosis proceeds via two major pathways: The death receptor pathway and the mitochondrial pathway (12). Mitochondrial apoptosis is initiated through alterations in mitochondrial structure and function, specifically by decreasing the mitochondrial transmembrane potential. Large quantities of cytochrome $c$ released from the mitochondria activate the caspase cascade, resulting in the activation of caspase-3 and apoptosis. A series of studies have suggested that the $\delta$-opioid receptor protects myocardial, neuronal and liver cells through inhibiting the mitochondrial apoptotic pathway $(5,13,14)$. In the present study, $\mathrm{H}_{2} \mathrm{O}_{2}$ was found to induce human liver cancer cell apoptosis through the mitochondrial pathway. Therefore, it was hypothesized that activated $\delta$-opioid receptors may regulate liver cancer cell apoptosis through the mitochondrial pathway.

Protein kinase C (PKC) is a serine/threonine kinase, which is widely expressed in human cells. In the unstimulated state, $\mathrm{PKC}$ is distributed in an inactive form in the cytoplasm. Following external stimulation, PKC is translocated from the cytoplasm to the plasma membrane and is activated. The PKC signaling pathway is involved in various biological activities, in which it mediates proliferation and differentiation in multiple cell types. Studies have shown that PKC has a protective effect in ischemic-preconditioned livers (15). Proliferation and apoptosis in normal liver and liver cancer cells are closely associated with the PKC pathway (16-18). A previous study by our group showed that activated $\delta$-opioid receptors and phosphorylated PKC participate in a common signaling pathway (5).

Extracellular-signal-regulated kinase (ERK) was the first mitogen-activated protein kinase (MAPK) to be identified and is the most studied MAPK member. ERK has two isoforms, ERK1 and ERK2. The two phosphorylation sites, a tyrosine residue and a threonine residue, are separated by a glutamic acid residue, thus the phosphorylation motif of ERK is TEY. p38 and c-Jun N-terminal kinase (JNK) are stress-activated MAPKs. Studies have shown that the ERK signaling pathway is involved in a wide range of biological activities and induces cell growth, proliferation and apoptosis (19). A growing body of evidence suggests that G-protein-coupled receptors (GPCRs) activate ERK through multiple mechanisms, including G-protein-dependent and G-protein-independent pathways. It is well established that ERK is a downstream effector of GPCR proteins, one of which is the $\delta$-opioid receptor. Studies have demonstrated that $\delta$-opioid receptors and ERK participate in the same downstream signaling pathways $(20,21)$. A study by $\mathrm{Xu}$ et al (22) showed that $\delta$-opioid receptors activate ERK through G-protein- or arrestin-dependent mechanisms. Therefore, in the present study it was hypothesized that $\delta$-opioid receptors may regulate apoptosis through activation of the ERK pathway.

In the present study, $\mathrm{H}_{2} \mathrm{O}_{2}$ was used to induce apoptosis in cultured human liver cancer cells in vitro. The role of $\delta$-opioid receptors in the regulation of apoptosis and its interrelation with PKC, mitochondria and the ERK pathway was then investigated in human liver cancer cells.

\section{Materials and methods}

Reagents. HepG2, HepH3B, SK-Hep-1 and LO2 cell lines were obtained from the Cell Bank of The Chinese Academy of Sciences (Shanghai, China). [D-Ala2, D-Leu5] enkephalin (DADLE), naltrindole, GF109203X, U0126, and MTT were purchased from Sigma-Aldrich (St. Louis, MO, USA). The 5',6,6'-tetrachloro-1,1',3,3'-tetraethylbenzimidazolylcarbocyanine iodide (JC-1) Mitochondrial Membrane-Potential Assay kit was purchased from Abcam Plc (Cambridge, MA, USA). RPMI-1640 and fetal bovine serum (FBS) were purchased from Gibco-BRL (Carlsbad, CA, USA). An Annexin V-fluorescein isothiocyanate (FITC) apoptosis kit was purchased from Bio-Rad (Hercules, CA, USA). Phosphorylated PKC (rabbit, monoclonal), Bcl-2 (rabbit, polyclonal), and Bcl-2-associated $\mathrm{X}$ (Bax) antibodies (rabbit, polyclonal) were purchased from Santa Cruz Biotechnology, Inc. (Santa Cruz, CA, USA). The following antibodies were used for western blot analysis: $\beta$-actin (sc-47778, diluted 1:1,000) and were obtained from Santa Cruz Biotechnology, Inc. Cytochrome $c$ and phosphorylated ERK antibodies were purchased from Abcam Plc. The present study was approved by the Ethics Committee of The Second Affiliated Hospital of Dalian Medical University (Dalian, Liaoning, China).

Cell culture. Liver cancer cells were seeded at a density of $1 \times 10^{6}$ cells $/ \mathrm{ml}$ in $\mathrm{T} 25$ cell-culture flasks and cultured in Dulbecco's modified Eagle medium (Gibco-BRL) supplemented with $10 \%$ FBS, penicillin and streptomycin in an incubator with $95 \% \mathrm{O}_{2}$ and $5 \% \mathrm{CO}_{2}$.

Experimental treatment. Liver cancer cells were cultured for $12 \mathrm{~h}$. Except for those in the control group, cells were treated with various concentrations of $\mathrm{H}_{2} \mathrm{O}_{2}(10,50,100,200$ and $400 \mathrm{mM}$ ) for $12 \mathrm{~h}$. While under $\mathrm{H}_{2} \mathrm{O}_{2}$ treatment, cells in the intervention groups were also treated with either the $\delta$-opioid-receptor agonist DADLE $(0.01,0.1,1.0$ or $10 \mu \mathrm{M})$, the $\delta$-opioid-receptor-specific inhibitor naltrindole, the PKC inhibitor GF109203X $(10 \mu \mathrm{M})$ or the ERK inhibitor U0126 $(10 \mu \mathrm{M})$ for $12 \mathrm{~h}$.

Cell viability assay. The MTT assay was used to analyze cell viability. Human liver cancer cells were treated with $200 \mathrm{mM} \mathrm{H}_{2} \mathrm{O}_{2}$ and various concentrations of DADLE for $12 \mathrm{~h}$ followed by incubation with $20 \mu 1$ MTT solution $[5 \mathrm{mg} / \mathrm{ml}$ in phosphate-buffered saline (PBS), pH 7.4] for $4 \mathrm{~h}$. The culture media was then removed and the formazan crystals in each well were fully dissolved in $200 \mu$ l dimethyl sulfoxide by vortexing for $10 \mathrm{~min}$. The absorbance value of each well was measured and recorded using a microplate reader (FLx $800^{\mathrm{TM}}$; Bio-Tek Instruments, Inc., Winooski, VT, USA) at a wavelength of $570 \mathrm{~nm}$.

Detection of apoptosis using Annexin V/propidium iodide (PI) double labeling. An Annexin V-FITC apoptosis kit was used according to the manufacturer's instructions. Cell death was detected using flow cytometry (FACS Vantage SE flow cytometer: BD Biosciences, Franklin Lakes, NJ, USA). Cells positive for Annexin $\mathrm{V}$ and negative for PI were considered to be early apoptotic cells. In brief, cells were harvested using 
$0.25 \%$ trypsin, washed with PBS three times, stained with $10 \mu \mathrm{l}$ Annexin V and $5 \mu \mathrm{l} \mathrm{PI}$ and incubated in the dark at room temperature for $15 \mathrm{~min}$. Cells were then analyzed using flow cytometry.

Detection of changes in mitochondrial membrane potential using JC-1 staining and flow cytometry. Cells were suspended at a concentration of $1 \times 10^{5}$ cells $/ \mathrm{ml}$, incubated with $10 \mu \mathrm{g} / \mathrm{ml}$ JC-1 staining solution, mixed thoroughly and incubated for 20 min. Non-conjugated JC-1 was removed using buffer, then cells were resuspended in buffer. Cells were analyzed using flow cytometry with an emission wavelength of $488 \mathrm{~nm}$. The FL1-h and FL2-h values represent the intensities of red and green fluorescence, respectively. The results were quantitatively analyzed using CellQuest software (BD Biosciences, Franklin Lakes, NJ, USA).

Isolation and purification of mitochondria. In each group, liver cancer cells were collected and suspended in pre-chilled extraction buffer [0.2 mol/1 mannitol, $50 \mathrm{mmol} / 1$ sucrose, $1 \mathrm{mmol} / \mathrm{l}$ EDTA, $1 \mathrm{mmol} / 1$ ethylene glycol tetraacetic acid, $10 \mathrm{mmol} / 1$ 4-(2-hydroxyethyl)-1-piperazineethanesulfonic acid, $\mathrm{pH} 7.4,50 \mathrm{mmol} / 1$ dithiothreitol, $5 \mathrm{mmol} / 1$ protease inhibitor cocktail and $1 \mathrm{mmol} / \mathrm{l}$ phenylmethylsulfonyl fluoride (PMSF)]. Following homogenization for 5-6 repetitions, cell homogenates were centrifuged at $1,000 \mathrm{x} \mathrm{g}$ for $10 \mathrm{~min}$ at $4^{\circ} \mathrm{C}$ and the supernatant was collected. The supernatant was then centrifuged at $7,000 \mathrm{x} \mathrm{g}$ for $10 \mathrm{~min}$ at $4^{\circ} \mathrm{C}$. The pellet was collected and the supernatant was centrifuged at $15,000 \mathrm{x} \mathrm{g}$ for $10 \mathrm{~min}$ at $4^{\circ} \mathrm{C}$. The pellet was collected and exposed to density gradient centrifugation using Nycodenz ${ }^{\circledR}$ (Axis-Shield, Oslo, Norway). The isolated mitochondria were then stored in a buffer solution at $-80^{\circ} \mathrm{C}$ until required.

Protein extraction and western blot analysis. Cells were lysed in pre-chilled lysis buffer $(50 \mathrm{mM}$ Tris- $\mathrm{HCl}, 137 \mathrm{mM} \mathrm{NaCl}$, $10 \%$ glycerol, $100 \mathrm{mM}$ sodium orthovanadate, $1 \mathrm{mM}$ PMSF (Gibco-BRL), $10 \mathrm{mg} / \mathrm{ml}$ aprotinin (Santa Cruz Biotechnology, Inc.), $10 \mathrm{mg} / \mathrm{ml}$ leupeptin (Amresco, Solon, OH, USA) and $1 \%$ Nonidet P-40 (Sigma; $\mathrm{pH}$ 7.4). Lysates were centrifuged at $12,000 \mathrm{x}$ g for $20 \mathrm{~min}$, after which the supernatant was collected and mixed with loading buffer (65 mM Tris-HCl, $\mathrm{pH} 6.8$, $3 \%$ SDS, $10 \%$ glycerol and $6 \mathrm{M}$ urea; Millipore, Billerica, MA, USA). Total protein concentrations were measured using a Pierce ${ }^{\mathrm{TM}}$ BCA protein assay kit (Pierce Chemical Co., Rockford, IL, USA). The electrophoresis buffer was supplemented with $\beta$-mercaptoethanol (Solarbio, Beijing, China) and bromophenol blue (Thermo Fisher Scientific, Rockford, IL, USA). Proteins were separated using $12 \%$ SDS-PAGE, transferred onto a polyvinylidene fluoride membrane (Bio-Rad), and incubated with primary antibodies at $4^{\circ} \mathrm{C}$ overnight. Protein bands were detected using an enhanced chemiluminescence method and the intensity of the protein bands were analyzed using a gel image-analysis system (Molecular Imager Gel DocTM XR+ system; Bio-Rad).

Total RNA extraction and quantitative polymerase chain reaction $(q P C R)$. Total RNA was extracted from the cells in each group using an RNAiso ${ }^{\mathrm{TM}}$ Plus kit (Takara Bio, Inc., Shiga, Japan) according to the manufacturer's instructions. Total RNA was subsequently quantified. The upstream primer for the $\delta$-opioid receptor was 5'-ACCAAGATCTGCGTGTTCCT-3', and the downstream primer was 5'-CGATGACGAAGATGTGGATG-3'. The upstream primer for the internal control, $\beta$-actin, was 5'-AAGGAAGGCTGGAAGAGTGC-3', and the downstream primer was 5'-CTGGGACGACATGGAGAAAA-3'. qPCR was performed using a Takara RNA PCR kit (AMV) Version 3.0 (Takara Bio Inc.). The reaction conditions were as follows: Pre-denaturation at $94^{\circ} \mathrm{C}$ for 2 min followed by 31 cycles of denaturation at $94^{\circ} \mathrm{C}$ for $30 \mathrm{sec}$, annealing at $94^{\circ} \mathrm{C}$ for $30 \mathrm{sec}$ and extension at $72^{\circ} \mathrm{C}$ for $30 \mathrm{sec}$, then a final extension at $72^{\circ} \mathrm{C}$ for $8 \mathrm{~min}$. PCR amplicons were separated on $1.5 \%$ agarose and analyzed using a gel imaging analysis system (Molecular Imager Gel DocTM XR+ system; Bio-Rad).

Caspase detection. The activity of caspase-3 was determined using the Caspase-3 activity kit (Beyotime Institute of Biotechnology, Haimen, China). To evaluate the activity of caspase-3, cell lysates were prepared following their respective treatment with various designated treatments. Assays were performed on 96-well microtitre plates by incubating $10 \mu \mathrm{l}$ protein of cell lysate per sample in $80 \mu \mathrm{l}$ reaction buffer [1\% NP-40, 20 mM Tris- $\mathrm{HCl}$ (pH 7.5), $137 \mathrm{mM}$ Nad and 10\% glycerol) containing $10 \mu \mathrm{l}$ caspase-3 substrate (Ac-DEVD-pNA) $\left(2 \mathrm{mM}\right.$ ). Lysates were incubated at $37^{\circ} \mathrm{C}$ for $4 \mathrm{~h}$.

Statistical analysis. All results are presented as the mean \pm standard error of the mean. The effects of the chemicals at different concentrations were analyzed using the analysis of variance method. Differences between groups were analyzed using the unpaired Student's t-test. A value of $\mathrm{P}<0.05$ was considered to indicate a statistically significant difference.

\section{Results}

$\mathrm{H}_{2} \mathrm{O}_{2}$-induced apoptosis in human liver cancer cells and the protective role of $\delta$-opioid receptor activation. In human liver cancer cells cultured in media containing $\mathrm{H}_{2} \mathrm{O}_{2}$ for $12 \mathrm{~h}$, the number of adhesive cells was observed to decrease and the morphology of the cells was observed to become round- or oval-shaped. These features were enhanced in a $\mathrm{H}_{2} \mathrm{O}_{2}$ concentration-dependent manner. Flow cytometry revealed that upon $\mathrm{H}_{2} \mathrm{O}_{2}$ treatment, the number of apoptotic cells increased in a concentration-dependent manner (Fig. 1A). The absorbance (A) $)_{570 \mathrm{~nm}}$ value of the liver cancer cells was also found to decrease in a concentration-dependent manner following $\mathrm{H}_{2} \mathrm{O}_{2}$ addition (Fig. 1B).

Caspase family members have key roles in apoptosis. In the present study, caspase- 3 and -8 expression were observed to increase in a concentration-dependent manner with $\mathrm{H}_{2} \mathrm{O}_{2}$ treatment, which was consistent with the increase in apoptosis observed (Fig. 1C). In order to investigate whether the $\mathrm{H}_{2} \mathrm{O}_{2}$-induced apoptosis was associated with the mitochondrial pathway in human liver cancer cells, mitochondrial and cytoplasmic levels of cytochrome $c$, as well as changes in mitochondrial membrane potential, were analyzed. $\mathrm{H}_{2} \mathrm{O}_{2}$ was found to significantly decrease the mitochondrial membrane potential (Fig. 1D). Furthermore, levels of cytochrome $c$ in the cytoplasm were observed to significantly increase 
A

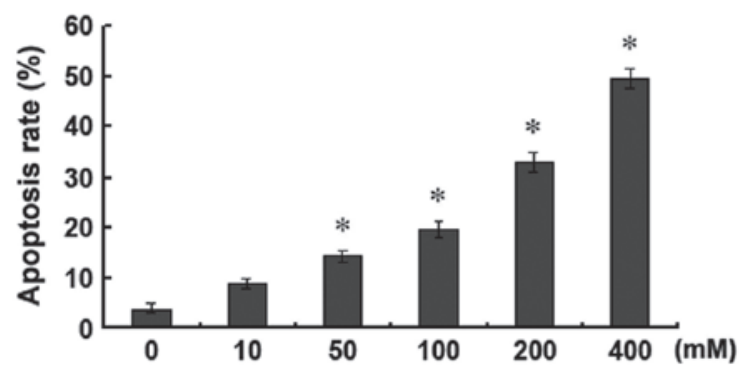

$\mathbf{C}$

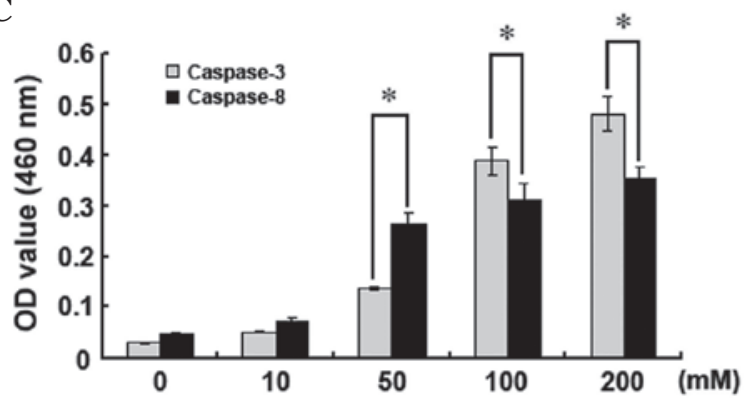

E

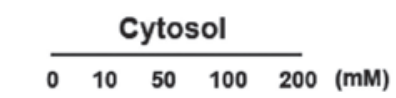

Cyt C

Actin

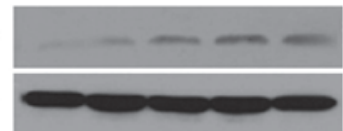

G

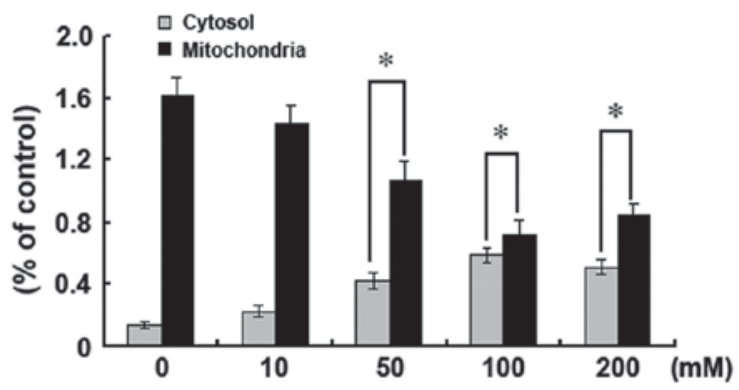

B

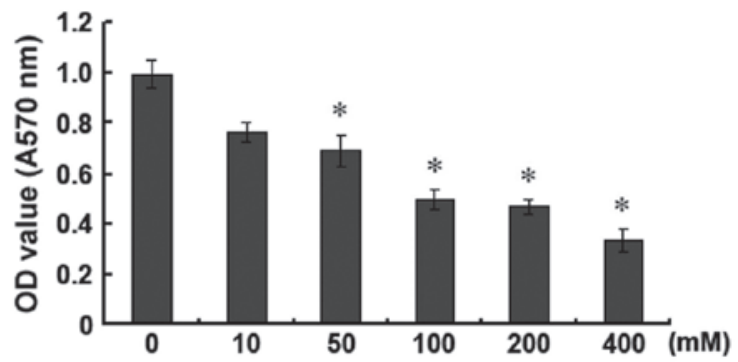

D

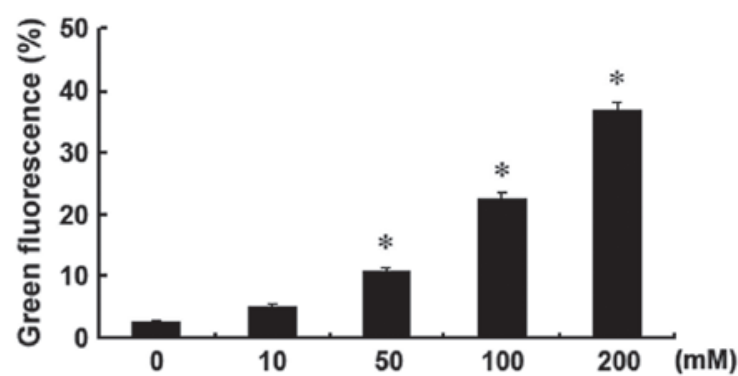

F

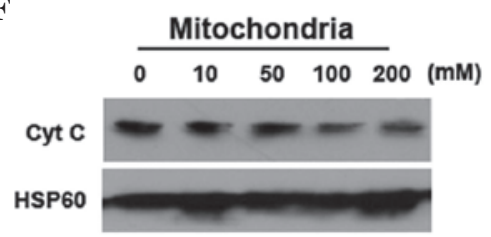

H



Figure 1. Treatment of human liver cancer cells with various doses of $\mathrm{H}_{2} \mathrm{O}_{2}(0,10,50,100,200$ and $400 \mathrm{mM}$ ) for $12 \mathrm{~h}$. (A) Detection of apoptosis using Annexin V/propidium iodide double labeling. (B) MTT assay to assess cell viability. (C) Detection of caspase-3 and -8 activities. (D) Analysis of changes in mitochondrial membrane potentials using JC-1 staining and flow cytometry. (E-G) Analysis of cytoplasmic and mitochondrial cyt $c$ expression using western blot analysis. (H) MTT assay to assess liver cancer cell survival following treatment with increasing concentrations of DADLE ( $0.01,0.1,1.0$ and $10 \mu \mathrm{M})$ with $\mathrm{H}_{2} \mathrm{O}_{2}$ treatment. ${ }^{*} \mathrm{P}<0.05$ vs. control group. Data are representative of three independent experiments. DADLE, [D-Ala2, D-Leu5] enkephalin; cyt $c$, cytochrome $c$; HSP, heat shock protein; OD, optical density.

(Fig. 1E and G), while those in the mitochondria gradually decreased (Fig. 1F and G). These findings suggested that $\mathrm{H}_{2} \mathrm{O}_{2}$-induced human liver cancer cell apoptosis proceeded through the mitochondrial pathway.

Upon treatment with $200 \mathrm{mM} \mathrm{H}_{2} \mathrm{O}_{2}$, the addition of various concentrations of DADLE was found to increase the $\mathrm{A}_{570 \mathrm{~nm}}$ value of liver cancer cells to various degrees. Increases in DADLE concentration from 0.01 to $1 \mu \mathrm{M}$ were observed to increase the $A_{570 \mathrm{~nm}}$ value of liver cells in a dose-dependent manner. However, at concentrations $>1 \mu \mathrm{M}$, no further increases were observed in the $\mathrm{A}_{570 \mathrm{~nm}}$ value of liver cancer cells. These findings suggested that DADLE had a dose-dependent protective effect against $\mathrm{H}_{2} \mathrm{O}_{2}$-induced apoptosis in human liver cancer cells, with a maximum effect at $1 \mu \mathrm{M}$ (Fig. 1H).

Effect of activated $\delta$-opioid receptors on human liver cancer cell apoptosis. To study the effect of activated $\delta$-opioid receptors on human liver cancer cell apoptosis, apoptosis was induced in liver cancer cells using $\mathrm{H}_{2} \mathrm{O}_{2}$. Cells were then treated with $1 \mu \mathrm{M}$ DADLE, a specific $\delta$-opioid receptor agonist. Annexin V-FITC/PI double-staining and flow cytometry revealed that the apoptosis rate of the cells treated with $200 \mathrm{mM} \mathrm{H}_{2} \mathrm{O}_{2}$ for $12 \mathrm{~h}$ was significantly increased compared with that in the control group. Furthermore, upon 
A
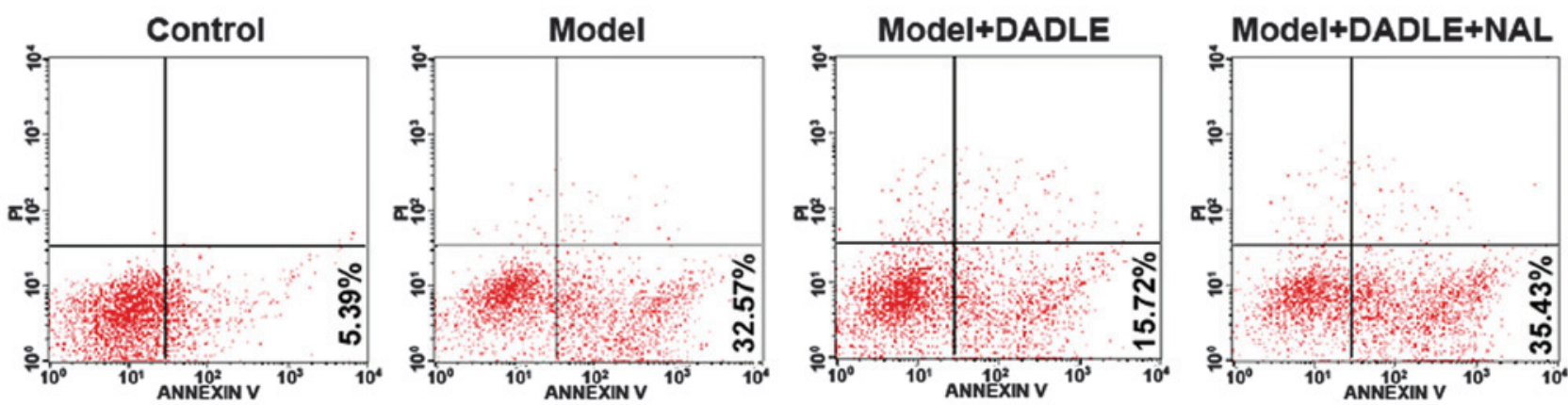

B

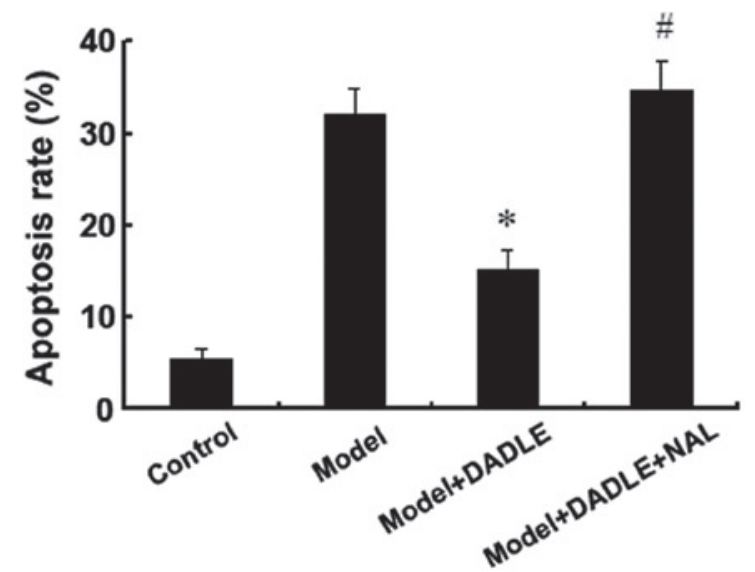

C

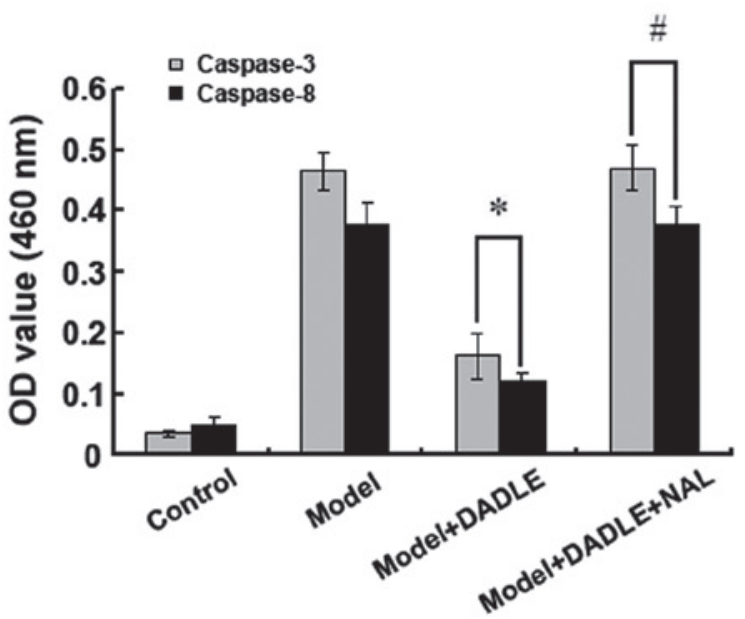

Figure 2. Treatment of cells with $200 \mathrm{mM} \mathrm{H}_{2} \mathrm{O}_{2}$ combined with $1 \mu \mathrm{M}$ DADLE or $10 \mu \mathrm{M}$ NAL. (A and B) Flow cytometric analysis of liver cancer cell apoptosis . (C) Detection of changes in caspase- 3 and -8 activities. ${ }^{*} \mathrm{P}<0.05$ vs. the model group; ${ }^{*} \mathrm{P}<0.05$ vs. the model + DADLE group. Data are representative of three independent experiments. NAL, naltrindole; DADLE, [D-Ala2, D-Leu5] enkephalin; OD, optical density.

DADLE-induced $\delta$-opioid receptor activation, the apoptosis rate was found to significantly decrease compared with the cells treated solely with $\mathrm{H}_{2} \mathrm{O}_{2}$. Moreover, when $\delta$-opioid receptor activation was inhibited using $10 \mu \mathrm{M}$ naltrindole, a $\delta$-opioid receptor antagonist, the DADLE-induced protective effect was reverted (Fig. 2A and B). Caspase-3 and -8 expression was observed to increase rapidly following $\mathrm{H}_{2} \mathrm{O}_{2}$ treatment. $\delta$-opioid receptor activation was found to significantly downregulate cytoplasmic caspase- 3 and -8 levels, and naltrindole was observed to inhibit this protective $\delta$-opioid receptor-induced effect (Fig. 2C). These findings suggested that $\delta$-receptor activation significantly inhibits $\mathrm{H}_{2} \mathrm{O}_{2}$-induced apoptosis in human liver cancer cells.

Activated $\delta$-opioid receptors inhibit human liver cancer cell apoptosis through the mitochondrial pathway. To investigate whether the molecular mechanisms underlying the inhibition of liver cancer cell apoptosis by activated $\delta$-opioid receptors are associated with the mitochondrial pathway, changes in mitochondrial membrane potential were analyzed. $\mathrm{H}_{2} \mathrm{O}_{2}$ treatment was found to gradually decrease the mitochondrial membrane potential in liver cancer cells. Concurrent $\delta$-opioid receptor activation and $\mathrm{H}_{2} \mathrm{O}_{2}$ treatment had no significant effect on the mitochondrial membrane potential (Fig. 3A). Cytochrome $c$ is released from mitochondria into the cytoplasm during apoptosis; therefore, western blot analysis was performed to investigate the cytoplasmic and mitochondrial cytochrome $c$ levels. Compared with the cells treated with $\mathrm{H}_{2} \mathrm{O}_{2}$ alone, upon activation of the $\delta$-opioid receptors with $\mathrm{H}_{2} \mathrm{O}_{2}$ treatment, cytoplasmic cytochrome $c$ levels were observed to decrease and mitochondrial cytochrome $c$ levels were found to increase (Fig. 3B and C). Furthermore, $\delta$-opioid receptor activation was observed to increase cytoplasmic Bax and decrease Bcl-2 expression (Fig. 3D and E). These findings suggested that DADLE may activate $\delta$-opioid receptors at the surface of the plasma membrane in liver cancer cells in order to stabilize mitochondrial membrane potentials and inhibit $\mathrm{H}_{2} \mathrm{O}_{2}$-induced apoptosis in human liver cancer cells.

$\delta$-opioid receptors affect human liver cancer cell apoptosis through the PKC/ERK pathway. In order to investigate whether $\delta$-opioid receptors activate the $\mathrm{PKC} / \mathrm{ERK}$ signaling pathway and whether inhibiting this signaling pathway alters the effect of $\delta$-opioid receptors on human liver cancer cell apoptosis, the phosphorylation levels of PKC and ERK were investigated. Following $\delta$-opioid receptor activation, phosphorylated PKC and ERK were observed to be significantly increased in the cytoplasm of human liver cancer cells (Fig. 4A and B), suggesting that $\delta$-opioid receptor activation may lead to phosphorylation of PKC and ERK. It has previously been reported that $\delta$-opioid receptor activation inhibits apoptosis in human liver cancer cells (23). However, in the present study, inhibiting 
$\mathbf{A}$
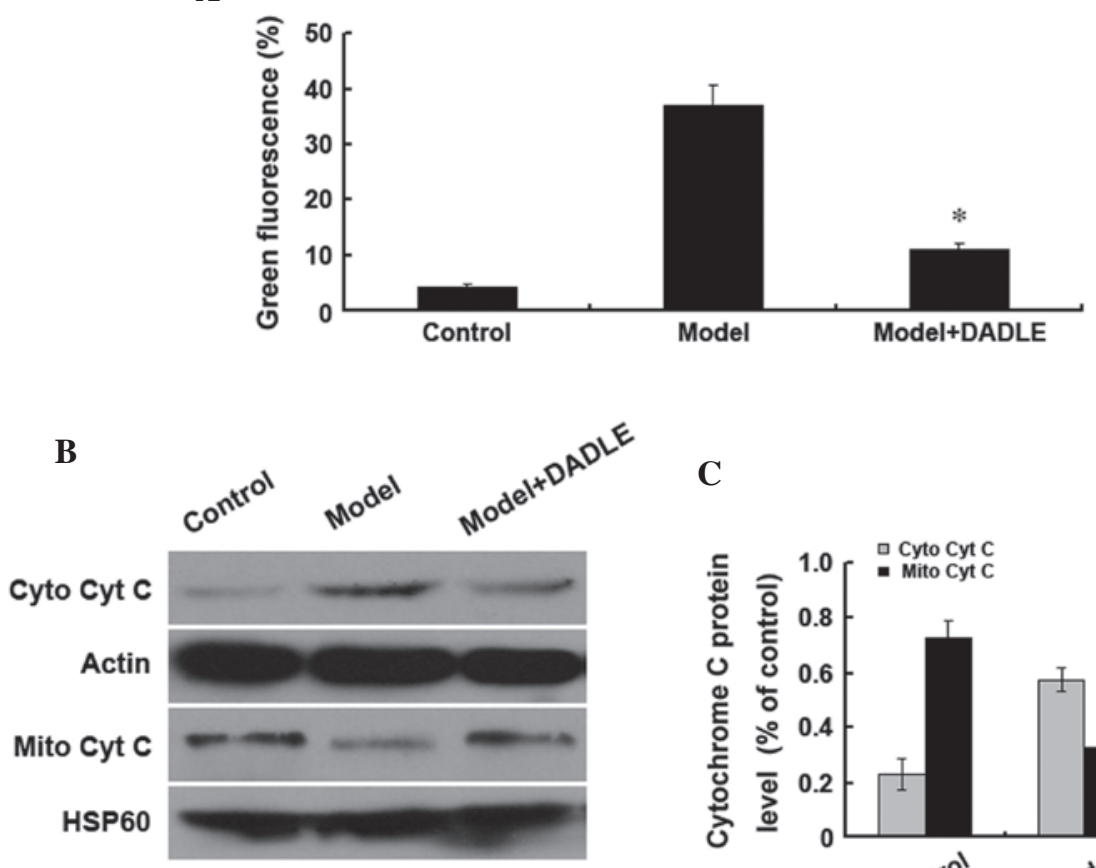

C
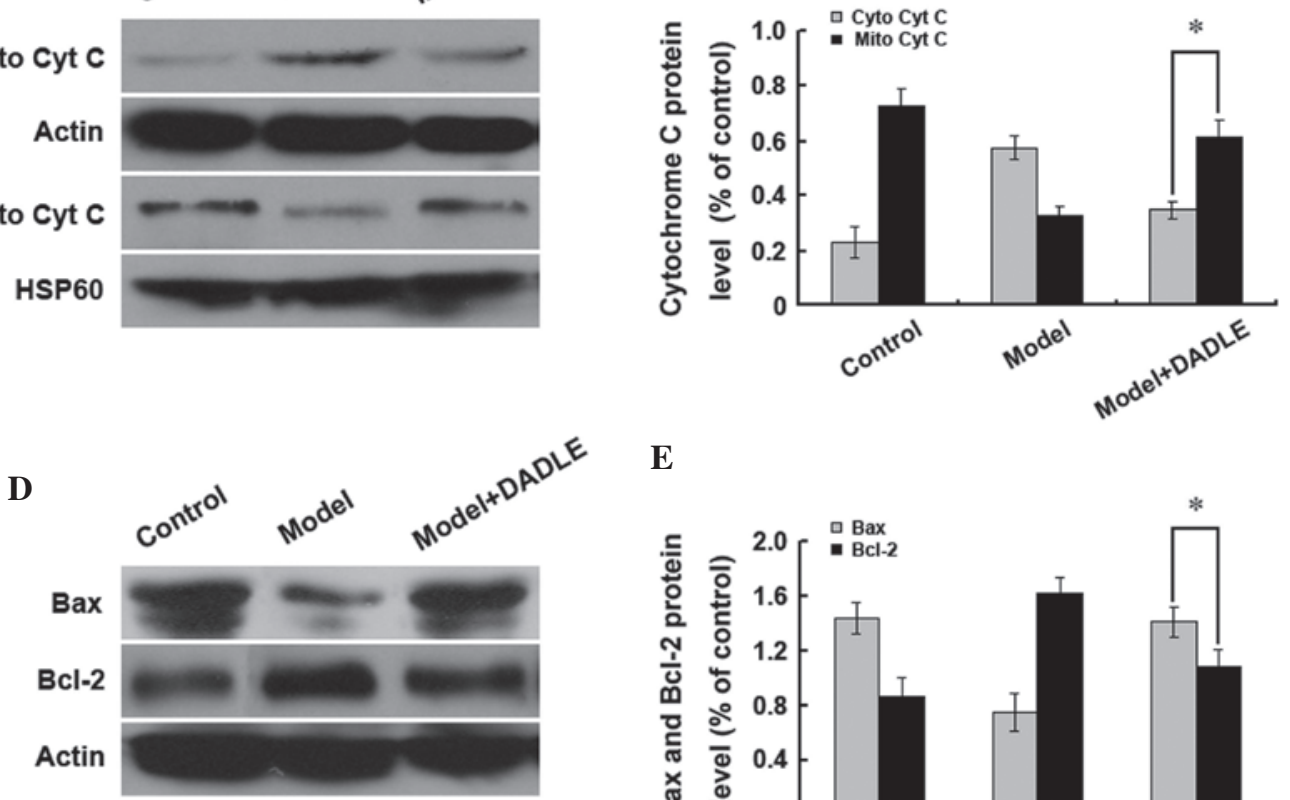

$\mathbf{E}$

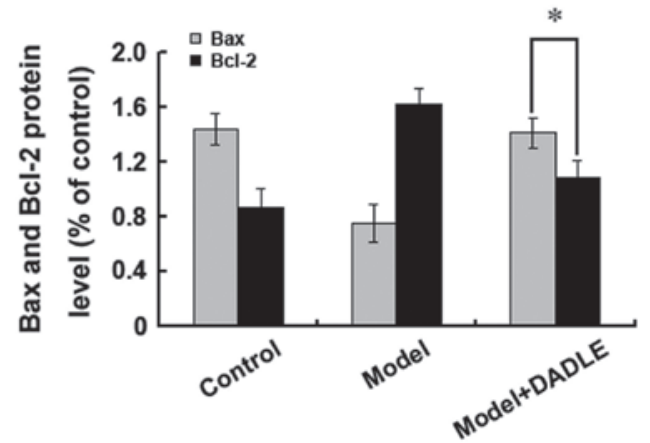

Figure 3. $\delta$-opioid receptor activation inhibits human liver cancer cell apoptosis through the mitochondrial pathway. Cells were treated with $200 \mathrm{mM} \mathrm{H}_{2} \mathrm{O}_{2}$ and the $\delta$-opioid receptor agonist DADLE $(1 \mu \mathrm{M})$. (A) JC-1 staining and flow cytometric analysis of changes in mitochondrial membrane potential. ${ }^{*} \mathrm{P}<0.05$ vs. the model group. (B-E) Western blot analysis of changes in cytoplasmic and mitochondrial (B and C) cyt $c$ protein expression and (D and E) Bax and Bcl-2 protein expression. Data are representative of three idependent experiments. DADLE, [D-Ala2, D-Leu5] enkephalin; cyt $c$, cytochrome $c$; Mito, mitochondrial; cyto, cytoplasmic; Bcl-2, B cell lymphoma 2; Bax, Bcl-2-associated X protein; HSP, heat shock protein; JC-1, 5',6,6'-tetrachloro-1,1',3,3'-tetraethylbenzimidazolylcarbocyanine iodide.

the PKC pathway was found to increase apoptosis and inhibit cell proliferation, regardless of the $\delta$-opioid receptor activation status. Inhibition of the ERK pathway was observed to have the same effect (Fig. 4C and D). These findings suggested that the PKC and ERK pathways are involved in mediating the protective effect of $\delta$-opioid receptors on $\mathrm{H}_{2} \mathrm{O}_{2}$-induced human liver cancer cell apoptosis.

$\delta$-opioid receptors are highly expressed in human liver cancer cells. To assess whether $\delta$-opioid receptors are expressed in human liver cancer tissues and cells, and whether they have a role in carcinogenesis, qPCR analysis was used to assess $\delta$-opioid receptor mRNA expression in 50 liver cancer samples. $\delta$-opioid receptors were found to be expressed in the 50 liver cancer samples, with the expression levels observed to be higher than those in the adjacent normal liver tissue. $\delta$-opioid receptor mRNA expression was also analyzed in several liver cancer cell lines (Fig. 5A). Western blot analysis further revealed that the protein expression of the $\delta$-opioid receptor was higher in liver cancer tissue than in the adjacent normal tissue. In addition, $\delta$-opioid receptor protein expression was found to be higher in the liver cancer cell lines than in the normal liver cell lines (Fig. 5B). These findings indicate that $\delta$-opioid receptors are highly expressed in human liver cancer tissues and cells and have an important role in liver cancer cell proliferation.

\section{Discussion}

The present study investigated the effect of activated $\delta$-opioid receptors on liver cancer cell apoptosis. Liver cancer cell apoptosis has an important role in liver tumorigenesis and liver 
A

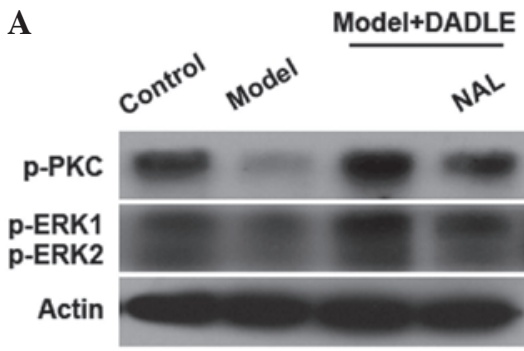

C

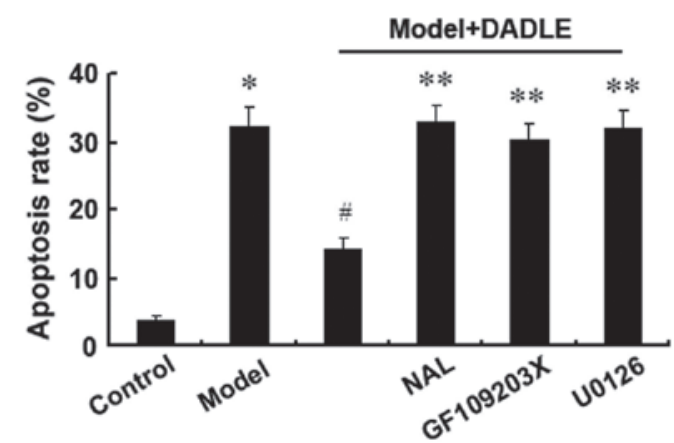

B

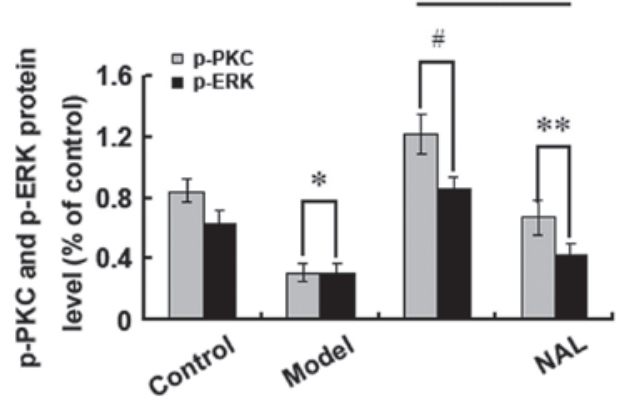

D

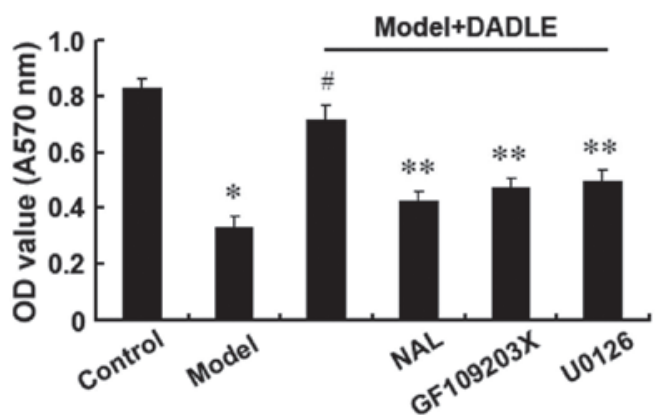

Figure 4. Effect of $\delta$-opioid receptor activation on human liver cancer cell apoptosis following inhibition of the PKC and ERK signaling pathways. Cells were treated with the $\delta$-receptor agonist DADLE $(1 \mu \mathrm{M})$ and either the PKC inhibitor GF109203X $(1 \mu \mathrm{M})$ or the ERK inhibitor U1026 (10 $\mu \mathrm{M})$. (A and B) Levels of phosphorylated PKC and ERK were detected using western blot analysis. (C) Flow cytometric analysis of liver cancer cell apoptosis. (D) MTT assay to assess liver cancer cell viability. ${ }^{*} \mathrm{P}<0.05$ vs. the control group; ${ }^{*} \mathrm{P}<0.05$ vs. the model group; ${ }^{* *} \mathrm{P}<0.05$ vs. the model + DADLE group. Data are representative of three independent experiments. DADLE, [D-Ala2, D-Leu5] enkephalin; NAL, naltrindole; p-, phosphorylated; PKC, protein kinase C; ERK, extracellular-signal-regulated kinase; OD, optical density.
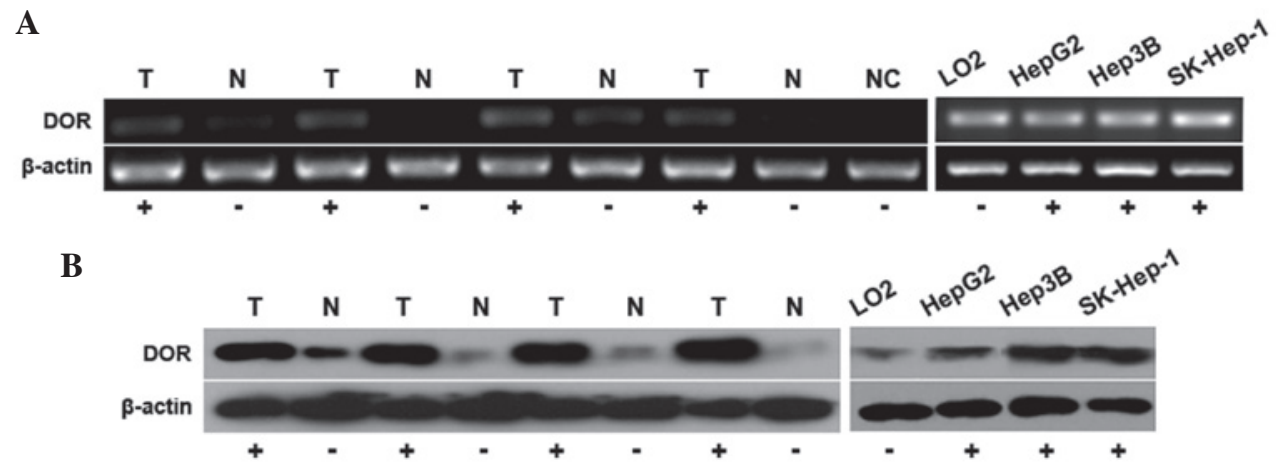

Figure 5. $\delta$-opioid receptor expression in human liver cancer tissues and liver cancer cell lines. (A) Quantitative polymerase chain reaction and (B) western blot analyses of $\delta$-opioid receptor expression in human liver cancer tissues, adjacent tissues, liver cancer cell lines and normal liver cells. Data are representative of three independent experiments. DOR, $\delta$-opioid receptor; T, tumor; $\mathrm{N}$, normal; NC, negative control.

cancer progression. Thus, identifying the mechanisms underlying liver cancer cell apoptosis, as well as promoting liver cancer cell apoptosis, may have important consequences with regard to treating liver cancer and protecting liver function. It has been shown that $\mathrm{H}_{2} \mathrm{O}_{2}$ is capable of inducing histological changes, including changes in cell morphology, cytoskeletal rearrangement, intracellular accumulation of reactive oxygen species and changes in mitochondrial function; all of which promote apoptosis (24). $\mathrm{H}_{2} \mathrm{O}_{2}$ is commonly used to induce apoptosis $(25,26)$ and in the present study, $\mathrm{H}_{2} \mathrm{O}_{2}$ was found to significantly induce apoptosis in human liver cancer cells in a time-dependent manner. $\mathrm{H}_{2} \mathrm{O}_{2}$ treatment also decreased the mitochondrial membrane potential, which was followed by the activation and release of cytochrome $c$ into the cytoplasm and an increase in caspase-3 expression. These findings indicated that $\mathrm{H}_{2} \mathrm{O}_{2}$-induced apoptosis is achieved through the mitochondrial pathway.

Opioid receptors are widely expressed across human tissues. A previous study by our group reported that $\delta$-opioid receptors are expressed in normal liver tissues, particularly in liver cancer tissues. $\delta$-opioid receptors predominantly participate in cell survival and proliferation. Su (27) showed that $\delta$-opioid receptors have a protective role in the liver, with $\delta$-opioid receptors reported to antagonize cholestasis in animal models (28). The previous study by our group showed that $\delta$-opioid receptors decreased normal liver cell 
apoptosis (5). In addition, endogenous opioid peptides have been found to promote liver cancer cell proliferation (8). This protective effect occurs through the activation of $\delta$-opioid receptors at the plasma membrane. The present study observed that $\delta$-receptor activation inhibited liver cancer cell apoptosis and downregulated caspase- 3 expression. This may be a protective mechanism for maintaining liver cancer cell self-repair functions.

Numerous studies have demonstrated that opioid receptors activate pertussis toxin-sensitive G-protein (29) and ATP-sensitive potassium channel (30) signaling pathways in order to exert their cellular functions. Furthermore, Zhao et al (31) showed that opioid receptors activate ERK in order to promote cell survival and proliferation. The present study indicated that $\delta$-opioid receptor activation increased PKC and ERK expression. Activated PKC has been reported to inhibit various types of apoptosis (32-34). The previous study by our group reported that $\delta$-opioid receptors were involved in cell proliferation and apoptosis in hepatic ischemia reperfusion injuries through activating PKC (5). Thus, PKC also participates in liver cancer cell proliferation and apoptosis. In the present study, $\delta$ receptor activation was found to significantly increase PKC expression. Furthermore, inhibition of PKC was observed to increase liver cancer cell apoptosis, independent of $\delta$-opioid receptor activation status. Previous studies have shown that activated $\delta$-opioid receptors activate the ERK signaling pathway $(35,36)$. ERK is a MAPK which is involved in cell proliferation, transformation and differentiation. Activated ERK activates transcription through the phosphorylation of p90 ribosomal S6 kinase and mitogen and stress activated protein kinase, as well as the transcription factors ELK-1 and signal transducer and activator of transcription 3, thereby inducing cell growth, proliferation and differentiation. The present study found that following $\delta$-opioid receptor activation, ERK phosphorylation levels significantly increased and liver cancer cell apoptosis decreased. However, inhibition of the ERK pathway significantly increased apoptosis in the liver cancer cells, regardless of $\delta$-opioid receptor activation. These findings suggested that PKC and ERK participated in the regulation of human liver cancer cell apoptosis through the $\delta$-opioid receptor.

A previous study by our group identified that $\mathrm{H}_{2} \mathrm{O}_{2}$ induced apoptosis through the mitochondrial pathway, which was similar to the findings of Li et al (37). In the present study, $\mathrm{H}_{2} \mathrm{O}_{2}$ stimulation was found decrease mitochondrial membrane potentials, increase cytochrome $c$ levels, increase the translocation of Bax from the cytoplasm to mitochondria and induce apoptosis. However, upon activation of the $\delta$-opioid receptors, $\mathrm{H}_{2} \mathrm{O}_{2}$-induced apoptosis was inhibited. These findings suggested that the protective role of $\delta$-opioid receptors in liver cancer cells was achieved through the mitochondrial pathway.

In conclusion, the present study demonstrated that $\mathrm{H}_{2} \mathrm{O}_{2}$-induced human liver cancer apoptosis occurred through the mitochondrial pathway. Furthermore, the activation of $\delta$-opioid receptors was found to protect cells from undergoing apoptosis through the mitochondrial pathway. In addition, the protective effect of $\delta$-opioid receptors on $\mathrm{H}_{2} \mathrm{O}_{2}$-induced apoptosis was found to be mediated through the PKC, ERK and mitochondrial pathways. Further elucidation of this apoptotic mechanism is important for understanding the role of $\delta$-opioid receptors in human liver cancer cell apoptosis and may have important implications for liver cancer treatment.

\section{Acknowledgements}

This research was supported by the National Natural Science Foundation of China (no. 81272368) and the Guangxi University of Science and Technology research project (no. 2013ZD046).

\section{References}

1. Schattenberg JM, Schuchmann M and Galle PR: Cell death and hepatocarcinogenesis: Dysregulation of apoptosis signaling pathways. J Gastroenterol Hepatol 26 (Suppl 1): 213-219, 2011.

2. Wang D, Wang H, Wu G, Yang Y, Yang J, Liu C and Wong TM: Protein kinase $\mathrm{C}$ mediates the effects of delta-opioid receptor stimulation on survival and apoptosis in neonatal cardiomyocytes cultured in serum-deprived condition. Pharmazie 64: 466-471, 2009.

3. Maslov LN, Barzakh EI, Krylatov AV, Chernysheva GA, Krieg T, Solenkova NV, Lishmanov AY, Cybulnikov SY and Zhang Y: Opioid peptide deltorphin II simulates the cardioprotective effect of ischemic preconditioning: role of $\delta_{2}$-opioid receptors, protein kinase C, and K(ATP) channels. Bull Exp Biol Med 149: 591-593, 2010.

4. Wang S, Duan Y, Su D, Li W, Tan J, Yang D, Wang W, Zhao Z and Wang X: Delta opioid peptide [D-Ala2, D-Leu5] enkephalin (DADLE) triggers postconditioning against transient forebrain ischemia. Eur J Pharmacol 658: 140-144, 2011.

5. Tang B, Zhang Y, Liang R, Yuan P, Du J, Wang H and Wang L: Activation of the $\delta$-opioid receptor inhibits serum deprivation-induced apoptosis of human liver cells via the activation of PKC and the mitochondrial pathway. Int J Mol Med 28: 1077-1085, 2011.

6. Neidle A, Manigault I and Wajda IJ: Distribution of opiate-like substances in rat tissues. Neurochem Res 4: 399-410, 1979.

7. Tang B, Li Y, Yuan S, Tomlinson S and He S: Upregulation of the $\delta$ opioid receptor in liver cancer promotes liver cancer progression both in vitro and in vivo. Int J Oncol 43: 1281-1290, 2013.

8. Avella DM, Kimchi ET, Donahue RN, Tagaram HR, McLaughlin PJ, Zagon IS and Staveley-O'Carroll KF: The opioid growth factor-opioid growth factor receptor axis regulates cell proliferation of human hepatocellular cancer. Am J Physiol Regul Integr Comp Physiol 298: R459-R466, 2010.

9. Boyella VD, Nicastri AD and Bergasa NV: Human hepatic met-enkephalin and delta opioid receptor-1 immunoreactivities in viral and autoimmune hepatitis. Ann Hepatol 7: 221-226, 2008.

10. Erol-Dayi Ö, Arda N and Erdem G: Protective effects of olive oil phenolics and gallic acid on hydrogen peroxide-induced apoptosis. Eur J Nutr 51: 955-960, 2012.

11. Hamdi Y, Kaddour H, Vaudry D, Bahdoudi S, Douiri S, Leprince J, Castel H, Vaudry H, Tonon MC, Amri M and Masmoudi-Kouki O: The octadecaneuropeptide ODN protects astrocytes against hydrogen peroxide-induced apoptosis via a PKA/MAPK-dependent mechanism. PLoS One 7: e42498, 2012.

12. Orrenius S: Mitochondrial regulation of apoptotic cell death. Toxicol Lett 149: 19-23, 2004

13. Jang Y, Xi J, Wang H, Mueller RA, Norfleet EA and Xu Z: Postconditioning prevents reperfusion injury by activating delta-opioid receptors. Anesthesiology 108: 243-250, 2008.

14. Raut A, Iglewski M and Ratka A: Differential effects of impaired mitochondrial energy production on the function of mu and delta opioid receptors in neuronal SK-N-SH cells. Neurosci Lett 404: 242-246, 2006.

15. Baldanzi G, Alchera E, Imarisio C, Gaggianesi M, Dal Ponte C, Nitti M, Domenicotti C, van Blitterswijk WJ, Albano E, Graziani A and Carini R: Negative regulation of diacylglycerol kinase theta mediates adenosine-dependent hepatocyte preconditioning. Cell Death Differ 17: 1059-1068, 2010.

16. Saberi B, Shinohara M, Ybanez MD, Hanawa N, Gaarde WA Kaplowitz N and Han D: Regulation of $\mathrm{H}(2) \mathrm{O}(2)$-induced necrosis by PKC and AMP-activated kinase signaling in primary cultured hepatocytes. Am J Physiol Cell Physiol 295: C50-C63, 2008. 
17. Wang Y, Schattenberg JM, Rigoli RM, Storz P and Czaja MJ: Hepatocyte resistance to oxidative stress is dependent on protein kinase C-mediated down-regulation of c-Jun/AP-1. J Biol Chem 279: 31089-31097, 2004.

18. Takai S, Matsushima-Nishiwaki R, Tokuda H, Yasuda E, Toyoda H, Kaneoka Y, Yamaguchi A, Kumada T and Kozawa O Protein kinase $\mathrm{C}$ delta regulates the phosphorylation of heat shock protein 27 in human hepatocellular carcinoma. Life Sci 81: 585-591, 2007.

19. Sancho P, Galeano E, Estañ MC, Gañán-Gómez I, Boyano-Adánez Mdel C and García-Pérez AI: Raf/MEK/ERK signaling inhibition enhances the ability of dequalinium to induce apoptosis in the human leukemic cell line K562. Exp Biol Med (Maywood) 237: 933-942, 2012.

20. Eisinger DA, Ammer H and Schulz R: Chronic morphine treatment inhibits opioid receptor desensitization and internalization. J Neurosci 22: 10192-10200, 2002.

21. Hong MH, Xu C, Wang YJ, Ji JL, Tao YM, Xu XJ, Chen J, Xie X, Chi ZQ and Liu JG: Role of Src in ligand-specific regulation of delta-opioid receptor desensitization and internalization. J Neurochem 108: 102-114, 2009.

22. Xu C, Hong MH, Zhang LS, Hou YY, Wang YH, Wang FF, Chen YJ, Xu XJ, Chen J, Xie X, Ma L, Chi ZQ and Liu JG: Serine 363 of the \{delta\}-opioid receptor is crucial for adopting distinct pathways to activate ERK1/2 in response to stimulation with different ligands. J Cell Sci 123: 4259-4270, 2010.

23. Tang B, Zhang Y, Liang R, Yuan P, Du J, Wang H and Wang $\mathrm{L}$ : Activation of the $\delta$-opioid receptor inhibits serum deprivation-induced apoptosis of human liver cells via the activation of PKC and the mitochondrial pathway. Int J Mol Med 28: 1077-1085, 2011.

24. Diestel A, Drescher C, Miera O, Berger F and Schmitt KR: Hypothermia protects $\mathrm{H} 9 \mathrm{c} 2$ cardiomyocytes from $\mathrm{H}_{2} \mathrm{O}_{2}$ induced apoptosis. Cryobiology 62: 53-61, 2011.

25. Yu H, Liu Z, Zhou H, Dai W, Chen S, Shu Y and Feng J: JAK-STAT pathway modulates the roles of iNOS and COX-2 in the cytoprotection of early phase of hydrogen peroxide preconditioning against apoptosis induced by oxidative stress. Neurosci Lett 529: 166-171, 2012.

26. Gao W, Xu K, Ji L and Tang B: Effect of gold nanoparticles on glutathione depletion-induced hydrogen peroxide generation and apoptosis in HL7702 cells. Toxicol Lett 205: 86-95, 2011.
27. Su TP: Delta opioid peptide[D-Ala(2),D-Leu(5)]enkephalin promotes cell survival. J Biomed Sci 7: 195-199, 2000.

28. Marzioni M, Alpini G, Saccomanno S, de Minicis S, Glaser S, Francis H, Trozzi L, Venter J, Orlando F, Fava G, Candelaresi C, Macarri G and Benedetti A: Endogenous opioids modulate the growth of the biliary tree in the course of cholestasis. Gastroenterology 130: 1831-1847, 2006.

29. Schultz JJ, Hsu AK and Gross GJ: Ischemic preconditioning and morphine-induced cardioprotection involve the delta (delta)-opioid receptor in the intact rat heart. J Mol Cell Cardiol 29: 2187-2195, 1997.

30. Pateliya BB, Singh N and Jaggi AS: Possible role of opioids and KATP channels in neuroprotective effect of postconditioning in mice. Biol Pharm Bull 31: 1755-1760, 2008.

31. Zhao M, Wang HX, Yang J, Su YH, Su RJ and Wong TM: delta-Opioid receptor stimulation enhances the growth of neonatal rat ventricular myocytes via the extracellular signal-regulated kinase pathway. Clin Exp Pharmacol Physiol 35: 97-102, 2008.

32. Allen TR, Krueger KD, Hunter WJ III and Agrawal DK: Evidence that insulin-like growth factor-1 requires protein kinase $\mathrm{C}$-epsilon, PI3-kinase and mitogen-activated protein kinase pathways to protect human vascular smooth muscle cells from apoptosis. Immunol Cell Biol 83: 651-667, 2005.

33. Agudo-López A, Miguel BG, Fernández I and Martínez AM: Role of protein kinase $\mathrm{C}$ and mitochondrial permeability transition pore in the neuroprotective effect of ceramide in ischemia-induced cell death. FEBS Lett 585: 99-103, 2011.

34. Peng Y,Hu Y, Feng N, Wang L and Wang X: L-3-n-butyl-phthalide alleviates hydrogen peroxide-induced apoptosis by $\mathrm{PKC}$ pathway in human neuroblastoma SK-N-SH cells. Naunyn Schmiedebergs Arch Pharmacol 383: 91-99, 2011.

35. Audet N, Paquin-Gobeil M, Landry-Paquet O, Schiller PW and Piñeyro G: Internalization and Src activity regulate the time course of ERK activation by delta opioid receptor ligands. J Biol Chem 280: 7808-7816, 2005.

36. Eisinger DA and Schulz R: Extracellular signal-regulated kinase/mitogen-activated protein kinases block internalization of delta-opioid receptors. J Pharmacol Exp Ther 309: 776-785, 2004.

37. Li R, Yan G, Li Q, Sun H, Hu Y, Sun J and Xu B: MicroRNA-145 protects cardiomyocytes against hydrogen peroxide $\left(\mathrm{H}_{2} \mathrm{O}_{2}\right)$-induced apoptosis through targeting the mitochondria apoptotic pathway. PLoS One 7: e44907, 2012. 